\title{
Memorial Issue for Professor K.B. Broberg
}

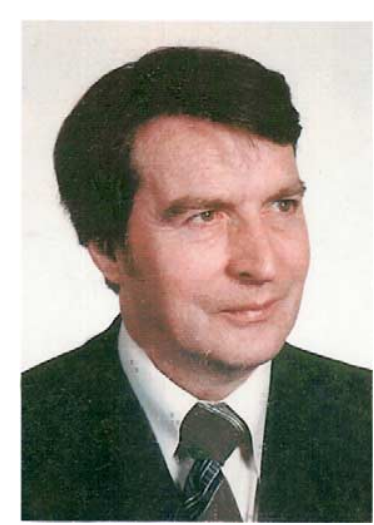

The present memorial issue was originally proposed by Professor Takeo Yokobori, Editor-in-Chief*, in order to esteem excellent achievements in fracture mechanics contributed by the late Professor Broberg, who was one of International Advisory Editorial Board members and among the authors for Vol. 1 No. 1 journal of Strength, Fracture and Complexity.

By courtesy of Dr. Michael Gilchrist of University College Dublin Ireland, the information on Professor Broberg is cited below from Dr. Gilchrist's preface at the Professor Broberg Memorial Symposium at University College Dublin on 9 May 2007.

Knut Bertram Broberg was born in Ballingsta Sweden on 4 February 1925. He graduated from the Royal Institute of Technology in 1949, and after working with the Royal Swedish Fortifications Administration, he moved to Lund Institute of Technology where Professor of Solid Mechanics from 1961 until his retirement in 1990 was his later position, during which he filled various positions including Faculty Dean, Prorector and Rector. He was elected Member of the Royal Swedish Academies of Sciences and of Engineering Sciences. He was also concerned with the international academic community throughout the world, for instance, Invited Scholar by Japan Society for Promotion of Science at Tohoku University, Sendai, Japan for three months in 1975, Sherman Fairchild Distinguished Scholar by California Institute of Technology for six months in 1976, and Visiting Professor at Brown University from 1979 to 1981. In 1991, after his retirement from Lund, he went to Dublin Ireland with his wife, Professor Anne Buttimer who joined the School of Geography University College Dublin, then he was invited as Senior Faculty Fellow at the Mathematical Physics Department UCD, where he much contributed to the mechanics community in Ireland. He passed away on 3 May 2005 at the age of 80 in Dublin.

Not going into details of his achievements as they are too much to introduce, only a few conspicuous ones will be described in what follows. His thesis "Shock waves in elastic and elastic-plastic media" in 1956 was so important in the study of nuclear explosions and earthquakes that it was even translated into Russian and Chinese later. In 1960 he published the epoch-making paper on the propagation of a brittle crack, which was the very first solution for a dynamically expanding crack. In 1999 he published

\footnotetext{
*Professor Emeritus, Tohoku University, Sendai, Japan and Member of The Japan Academy and Engineering Academy of Japan, respectively.
} 
his monumental treatise on the foundation of fracture mechanics: Cracks and Fracture. An example showing his research versatility was his paper on "Blisters - a wallpapering problem" in 1995. His last paper was in the September 2006 issue of Pure and Applied Geophysics 163 1867-1879.

Finally all the submitting authors are acknowledged. Professor Wang Li-li of Ningbo University China is appreciated for his contribution to paper submission. Dr. Michael Gilchrist of University College Dublin is grateful for the information on Professor Broberg. Mrs. Broberg, Professor Anne Buttimer, is also appreciated for her encouragement.

Guest Editors Akira Kobayashi Professor Emeritus The University of Tokyo, Tokyo, Japan and Member of Engineering Academy of Japan A. Toshimitsu Yokobori Jr. Professor Tohoku University, Sendai, Japan 